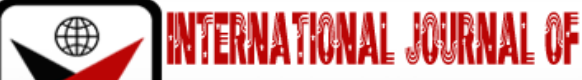

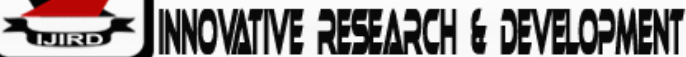

ISSN 2278-0211 (Online)

\section{Effect of Titanium on Itakpe Iron Ores Using Mathematical Modeling Approach with Respect to Second Law of Thermodynamic Principle}

\author{
Achuenu Ifeanyi \\ Technologist, Department of Mining Engineering, University of Jos, Nigeria \\ Komolafe Kayode \\ Lecturer, Department of Mining Engineering, University of Jos, Nigeria
}

\begin{abstract}
:
The objectives of this study were to evaluate the effect of titanium on iron ores and how it controls the strength, magnetization, and density (grade) of iron ores. The effectiveness of iron ores in Extractive Industry depends on the ratio of titanium to iron in the solid solution during crystallization of magma with respect to Gibbs free energy and can be mathematically expressed as, $\left[\mathrm{Fe}_{3-x} \mathrm{Ti}_{x}\right] \mathrm{O}_{4}$ and $\left[\mathrm{Fe}_{2-x} \mathrm{Ti}_{x}\right] \mathrm{O}_{3}$. Methodologically, $1 \mathrm{Kg}$ of each of five samples of iron ores were collected from Itakpe iron ore, which were pulverized and were compared with those that were obtained from $20 \mathrm{Kg}$ of Cassiterite after processing with the help of ordinary hand magnet of about 0.01Tesla. Findings have shown that, the high magnetization by ordinary hand magnet, with low strength and greater density of Itakpe iron ore indicated that the ores have not been affected by titanium. Conversely, the low magnetization by hand magnet with greater strength and lower density indicated that the ores from cassiterite have been affected by titanium. In conclusion, the presence or absence of titanium in an iron ore determines the types of magnetic separators used to separate the ores, as well as their genetic rock origin, in which the amount of titanium in iron ore increased from Basic, with $\Delta G=0$, e.g., basalt to more Acidic, with $\Delta G>0$, e.g., granite which gives the account that oceanic basalt is more magnetic, more dense, weaker strength than the granite. After comparative analyses between Itakpe iron ores and cassiterite in Jos Plateau state, using magnetism, strength, and density to appraise the iron ores according to titanium to iron ratio, concise valuable substantive empirical novel models were developed and can be employed to study iron ore. These concise empirical novel models were, "Matrix equations," Oxidation and the Titanization, as well as Periodic Table of an iron ore, and can be recommended to study the effect of titanium on iron ores and the application can improve mineral processing in extractive Industry
\end{abstract}

Keywords: Periodic table of an iron ore, oxidation, Titanization, magnetization, strength, density

\section{Introduction}

\subsection{Background to the Study}

Mathematical models involve the use of equations consisting of variables and constants according to Hubbert

(1937). Geo mathematics, in its broadest sense includes all applications of mathematics to studies of the earth's crust.

In geo mathematical problems, one usually asks if there are theoretical reasons to assume the certain variables are related to one another and if theoretical geology can provide guidelines for statistical models to be fitted to the data. Generally, the geologist can observe and reconstruct only part of a very complicated process involving many variables that have taken place in the course of time under changing circumstances.

In practice, the resulting mathematical model may then consist of fitting to the data a few linear terms out of a Taylor expansion ([2.21]) for the mainly unknown geological process. Quantitative geologic considerations are indispensable, first for selection of the variables to be measured, for designing the mathematical model and later for interpretation and evaluation of the results.

Modeling is process of representing a real-world object as set mathematical equations that is representing three dimensional objects especially in computer (ford, 2009). Mathematical models involve the use of equations consisting of variables and constants according to Hubbert (1937). Krumbein and Grayhill (1965) have distinguished three types of models in geology: (1) scale-models; (2) conceptual models; and (3) mathematical models. According to Nakayama and Vansiclen, (1981); Ungerer et al., (1984), deterministic models seek to identify and quantify all variables of the system and thus predict its behaviour by establishing values or limit for each system. Mathematical modeling in this context is the application of mathematical equations of numerical values to chemical elements in its algebraic form to produce a material of a particular IUPAC nomenclature according to Achuenu, (2018 unpublished). 
Rocks contain thousands of tiny ferrimagnetic minerals grains. The compositions of ferrimagnetic minerals are mostly transition metals in which oxygen atoms fill the lattice space of the metal. These are iron (Fe), titanium (Ti), manganese ( $\mathrm{Mn}$ ), cobalt (Co) Nickel (Ni), Zircon (Zr), Niobium (Nb) and tantalum (Ta). These are magnetic elements, because of the presence of extra electrons in the d-orbital below the outer orbital, burns, Clark and Fyfe, (1964). The magnetic minerals to be modeled are: Wustite $(\mathrm{FeO})$, Rutile $\left(\mathrm{TiO}_{2}\right)$, Magnetite $\left(\mathrm{Fe}_{3} \mathrm{O}_{4}\right)$, Haematite $\left(\mathrm{Fe}_{2} \mathrm{O}_{3}\right)$, Ulvospinel $\left(\mathrm{Fe}_{2} \mathrm{TiO}_{4}\right)$, Ilmenite

Because of presence of oxygen fugacity in the magma, iron will undergo the following series of oxidation, as shown in equation (1).

$\quad \mathrm{Fe}^{0} \stackrel{-e}{\rightarrow} \mathrm{Fe}^{+} \stackrel{-e}{\rightarrow} \mathrm{Fe}^{2+} \stackrel{-e}{\rightarrow} \mathrm{Fe}^{3+}$

Equation (1) is called oxidation reaction series of iron ore.

The iron ions at three oxidation states above are called iron (i) oxide iron (ii) oxide, and iron (iii) oxide, the iron (i)oxide is unstable and transient and not found in natural compound. The oxides are in the forms of haematite $\left(\mathrm{Fe}_{2} \mathrm{O}_{3}\right)$, magnetite $\left(\mathrm{Fe}_{3} \mathrm{O}_{4}\right)$, wustite $(\mathrm{Fe} 0)$

The order of increasing oxidation is as shown below;

Wustite $(\mathrm{Fe} 0)<$ magnetite $\left(\mathrm{Fe}_{3} \mathrm{O}_{4}\right)<$ haematite $\left(\mathrm{Fe}_{2} \mathrm{O}_{3}\right)$

As noted from fundamental of Geophysics by William Lowrie, Reprinted (2004), Titano-magnetite - hematite is the name of the family of iron oxide minerals described by the general formula as shown below;

- $\quad$ Magnetite: [X3-x Yx]04

- $\quad$ Hematite: $[\mathrm{X} 2-\mathrm{X}\urcorner \mathrm{Yx}] 03$

These indicate the ionic replacement of two Fe3+ by one Fe2+ and one Ti4+ion can take place in solid-solution series according to Goldschmidt (1937) as shown in Table 2.

\subsection{Justification}

The concept of this mathematical model is an empirical model that would be developed in this research to iron ore and it is grouped into a table called Periodic Table of an iron ore. It is a method developed as a complementary model to Mendeleev Periodic Table of an element to help students of mineralogy, petrology and other courses related to crystal geology as well as elementary science such as secondary school chemistry and Physics in order to understand the formation of iron ore from igneous and sedimentary rocks. It involves using mathematical equations, to calculate the empirical formula of each iron ore that formed during crystallization from the melt and sediment as shown in Figure 1. It also helps students to classify, name and understand genetic origin of the iron ores. This research when completed would proffer complementary model to Mendeleev Periodic Table and would be one of the simplified models to study mineralogy, and petrology of iron ore as well as its application to geochemistry and mineral exploration. Mendeleev classifies elements and arranged them according to their increasing atomic weight and they are independent of any conditions (condition independency). While this research uses two series of reactions with respect to titanium to iron ratio to classify iron ore with increasing and decreasing magnetization, strength, and density and they are condition dependency such as temperature, pressure and energy as shown in Figure 1. The two series of reactions are 0xidation, and Titanization reactions and these two series of reactions are used to design the conceptual frame work as shown in Figure 1.

\subsection{Statement of the Problem}

Goldschmidt classified elements according to the preferred host into a phase in the Periodic Table, but Mendeleev arranged these elements in the Periodic Table according to their increasing atomic number, without any change of conditions in which these elements formed. This means that, they do not depend on temperature and pressure as well as energy to form that is, they are in their own physical and chemical states at all conditions in the planetary bodies. Conversely minerals depend on these conditions to form, but the problem is that, there are no proper mathematical documentations that explain the time of formation of these minerals with respect to these conditions.

In order to overcome or resolve to this problem, mathematically;

- The temperature at which each mineral crystallizes, during crystallization from the melt and sediment must be mathematically documented

- The Pressure at which each mineral crystallizes, during crystallization from the melt and sediment must be mathematically documented

- The energy at which each mineral is at equilibrium after formation, during crystallization from the melt and sediment must be mathematically documented

- This means that, Periodic Table of iron ore depends on these conditions of change of temperature, pressure and energy of stabilization and the parameters used to establish this relationship are;

- Magnetization

- Strength

- density 


\subsection{Aim and Objectives of the Study}

The main aim of this research is the application of mathematical model to establish a relationship between the iron ores of Itakpe in Kogi state and iron ores in cassiterite of Jos Plateau state using titanium to iron ratio with respect to thermodynamic principle and classify them into a table called Periodic Table of an iron ore and the objectives are;

- Measuring magnetization of the ore in which its magnetic field is subjected to ordinary hand magnet of about 0.0T.

- Measuring the density of the ore using Archimedes' principle

- Measuring the strength of the ore using triaxial testing machine

- Using mathematical equations to ascertain the values measured from magnetization, density, strength and energy.

\subsection{Conceptual Frame Work}

The concept of this model indicates two series of reactions which are Oxidation, and Titanization reactions series and this is shown in Figure 1. From Figure 1 the following deductions are made;

- Oxidation represents the horizontal axis while Titanization represents the vertical axis.

- Oxidation is the reaction series that takes place in basalt and sedimentary rock

- Titanization is the reaction series that takes place in andesite and granite.

- The stability of minerals increases across the Figure from left to the right and increases down the Figure from top to bottom.

- The temperature of crystallization of minerals decreases across the Figure from left to the right and decreases down the Figure from top to bottom.

- Solid solution is the process of exchanging one ion to the other in molten form with respect to temperature.

- Minerals that form during oxidation are wustite, magnetite, and haematite

- Minerals that form during titanization are rutile, ulvospinel and ilmenite

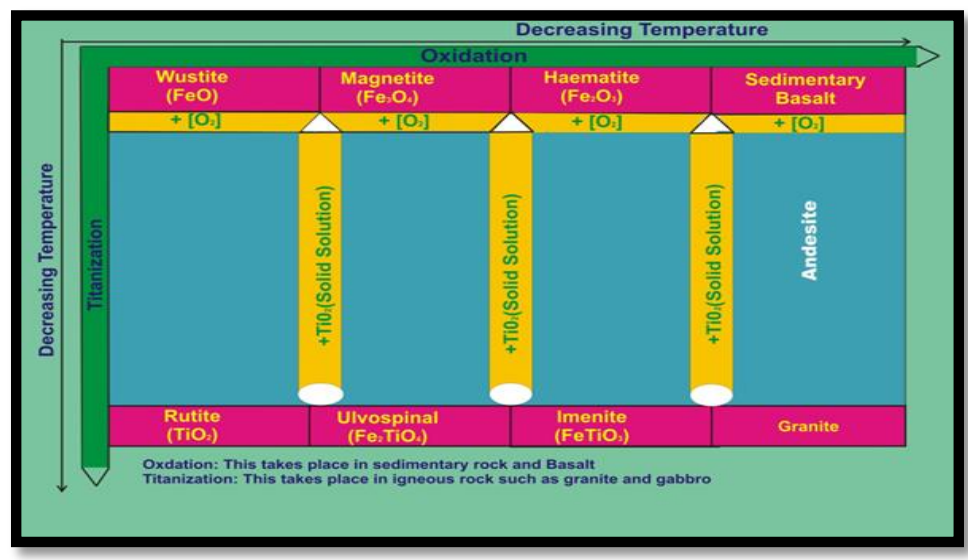

Figure 1: Design Model

\subsubsection{Definition of Terms}

- Matrix: Mathematical representation of rectangular array of minerals in rock (ore) arranged in rows and columns with respect to Gibbs free energy

- Oxidation: This is the addition of oxygen to the ores as temperature drops during crystallization of magma at a given Gibbs free energy with respect to temperature and pressure.

- Titanization: At a given Gibbs free energy with respect to temperature and pressure, Titanization in this context is the process involving mathematical substitution of iron by titanium in equal proportion in solid solution during chemical process in the magma to produce a natural durable, high strength, lightweight alloys of iron ores that enhance the life of iron ores when exposed to wear, e.g., ilmenite and ulvospinel.

"GEOMATHEMATICAL MODELING as used in this research, is the system of model of computation of numerical values to chemical element in its algebraic form to produce a material of a particular IUPAC nomenclature (name)" e.g. iron ore according to Achuenu, (2018 unpublished).

NOTATIONS: $\mathrm{X}=\mathrm{Fe}$

$$
\begin{aligned}
& Y=T i \\
& T=\text { tesla } \\
& N=\text { number of moles } \\
& \Delta G=\text { change in Gibbs free energy. }
\end{aligned}
$$

\section{Literature Review}

\subsection{Introduction}

Krumbein and Grayhill (1965) have distinguished three types of models in geology: (1) scale-models; (2) conceptual models; and (3) mathematical models. Traditionally, geologists have been concerned with scale-models and conceptual models mainly. 
Examples of scale-models are the geological map and cross-sections where the spatial variability of attributes is represented at a reduced scale for topographic surface and vertical planes, respectively. Geological processes also can be represented by scale-models. A classic discussion of this subject was given by Hubbert (1937). Conceptual models are mental images of variables and constants. They are statistical or deterministic depending on whether one or more random variables are used in the equation or systems of equations to express uncertainty. Mathematical equations generally can be represented geometrically by curves or surfaces.

The three types of models listed are not mutually exclusive. Scale-models can be based on mathematical criteria and conceptual models may be partly or entirely quantitative. Most mathematical models in geology have some important aspects of uncertainty and for this reason, are statistical. The problem may consist of eliminating the random variations from data so that a deterministic expression is retained representing the relationship between averages for assemblages of attribute rather than between single features. Statistical components or the uncertainty provide a way of expressing a range of different extrapolations for single features, all of which are possible, but with different probabilities of occurrence. This method replaces that of extrapolating a phenomenon with absolute certainty.

Geology differs from physics, chemistry and other sciences in that the possibility of doing controlled experiment is more limited. The observations are restricted to a record of past events, making geology a historical science. Generally, the final product of many interrelated processes is exposed at the surface of the earth in an imperfect manner. These mainly physical-chemical processes seldom reached a state

Younger igneous rocks, consisting largely of plutonic and volcanic components, form the Jurassic alkaline ring complexes of Jos Plateau, which are the major sources of the Nigerian tin and associated ores, iron ores (Macleod, etal.1971). The bulk of the cassiterite was obtained from alluvial deposit on Jos Plateau general considered to be derived from the Jurassic biotite granites of the ring complexes. Only very few economic deposits of tin were known in the older basement rocks. The ore is currently being processed using magnetic and gravity methods.

Itakpe iron ore deposit is a magnetite - haematite mineral consisting of 14 ore layers of economic value in grade predominantly 14.8 - 41\% Fe with an overall average of 36\% Fe. It is located at latitude $07^{0} 36^{\prime} 20^{\prime \prime} \mathrm{N}$ and longitude 06018'35" E in Okechi local Government Area of Kogi state

\subsection{Modeling}

A model is a simplified version of reality that is useful as a tool. There are primarily two types of models namely qualitative and quantitative models. Qualitative models are mostly descriptive and use of standard geological techniques of mapping and construction of cross-sections. The quantitative models are broadly of two types: deterministic and probabilistic models. According to Yukler and Welte, (1980); Welte and Yukler, (1981); Nakayama and Vansiclen, (1981); Ungerer et al., (1984), deterministic models seek to identify and quantify all variables of the system and thus predict its behavior by establishing values or limit for each system. They require large number of input data and therefore worthwhile only when extensive exploration has already been carried out. In probabilistic models, both input and output data are presented as probability distributions as according to Bishop et al., (1983); Sluijk and Nederlof, (1984).

A successful model strikes a balance between realism and practicality. Geologic maps constitute a familiar class of models. To map sedimentary section, a geologist collects data at certain outcrops. He casts his observations in terms of the local stratigraphy, which is itself a model that simplifies reality by allowing groups of sediments to be lumped together into formations. He then interpolates among his data point and projects beneath them to infer positions for formation contacts, faults and so on across his study area.

The first and most critical step in developing a geochemical model is conceptualizing the system or process of interest in a useful manner. By system, we simply mean the portion of the universe that we decide is relevant. The composition of a closed system is fixed, but mass can enter and leave an open system. A system has an extent, the amount of fluid and mineral considered in calculation.

The "art" of geochemical modeling is conceptualizing the model in a useful way as shown in Figure 6. This figure shows schematically the basis for constructing a geochemical model. The heart of the model is equilibrium system, which remains in some forms of chemical equilibrium, throughout the calculation. The equilibrium system contains an aqueous fluid and optionally one or more minerals. The temperature and composition of the equilibrium system are known at beginning of the model which shows the system's equilibrium state to be calculated Pressure also affects the equilibrium state, but usually in a minor way under near-surface condition, (Helgeson, 1969 but also Hemley et.al, 1989), unless a gas phase is present.

In the simplest class of geochemical models, the equilibrium exists as a closed system at a known temperature. Such equilibrium models predict the distribution of mass among species and minerals as well as species activities, the fluid saturation state with respect to various minerals and fugacities of different gases that can exist in the chemical system. In this case the initial equilibrium system contributes the entire geochemical model.

Conceptualizing a geochemical model is a matter of defining:

- The nature of equilibrium to be maintained

- The initial composition and temperature of the equilibrium system.

- The mass transfer or temperature variation to occur over the course of the reaction process envisioned.

\subsection{Equilibrium Modeling}

According to Pitzer and Brewer, (1961), and Denbigh (1971), a system is in equilibrium when it occupies a specific region of space within which there is no spontaneous tendency for change to occur. 
Geochemical models can be conceptualized in terms of certain false equilibrium states (Barton et.al, 1963; Helgeson, 1968). A system is in metastable equilibrium when one or more reactions proceed toward equilibrium at rates that are vanishingly small on the time scale of interest. Metastable equilibrium commonly Figure in geochemical model. In calculating the equilibrium state of natural water from a reliable chemical analysis, for example, we may find that the water is supersaturated with respect to one or more minerals. The calculation predicts that the reaction to precipitate these minerals have not progressed to equilibrium.

\subsection{Classification of Elements in Periodic Table}

Goldchmidt (1947), classifies chemical elements within the Earth according to their preferred host phases into lithophile (rock-loving), siderophile (iron- loving), chalcophile (ore - loving) and atmophile (gas- loving).

Mendeleev (1869) arranged 63 elements according to their increasing atomic number in several columns, noting recurring chemical properties across them.

Alexandre (1862), a geologist arranged elements in a spiral on a cylinder by order of increasing atomic weight.

John (1866) noting that when the elements were listed in order of increasing atomic weight, similar physical and chemical properties recurred at intervals of eight.

Otto (1960) arranged them in a continuous spiral with hydrogen at the centre and transition metals, lanthanides and actinides occupying peninsulas.

Courtines periodic classification (1925), Wringley's system (1949), Giguere's Periodic helix (1965), Dufour Periodic Tree (1996), Stoewe's physicists Periodic Table (1989), Rayner-Canham's unruly inorganic chemists Periodic Table (2002) which emphasizes trends and patterns and unusual chemical relationship and properties. Janet's left step Periodic Table (1928).

\subsection{Thermodynamic Principle}

In thermodynamic, the Gibbs energy $(G)$ is the thermodynamic potential that is minimized when a system reaches chemical equilibrium at constant pressure and temperature. Gibbs energy is the energy available to do work (Gibbs, 1873).

According to second law of thermodynamic, for systems reacting at standard conditions for temperature and pressure, there is a general natural tendency to achieve a minimum of the Gibbs free energy (Gibbs, 1873).

\section{Theoretical Framework}

Geomathematically and technically, Periodic Table of an ore is designed to classify iron ore into groups according to titanium to ion ratio based with respect to thermodynamic on the assumptions that

- At equilibrium, all minerals must attain, at least free Gibbs energy $(\Delta \mathrm{G})$

- At an igneous condition titanium is present at a controlled temperature under isobaric condition.

- At sedimentary condition titanium is absent; except that when the temperature of sedimentary rock is heated up to the igneous temperature that would precipitate titanium from the melt or sedimentary rock is the product of disintegration of igneous rock.

Igneous rocks solidify at temperature well above $1000^{\circ} \mathrm{C}$ (Bowens 1928). Both titanomagnetite and hemoilmenites crystallize at above $1300^{\circ} \mathrm{C}$. Above $600^{\circ} \mathrm{C}$, there is complete solid-solution between magnetite and ulvospinel and above $800^{\circ} \mathrm{C}$ between haematite and ilmenite as in equations (6) and (7) respectively.

- $\mathrm{Fe}_{(\mathrm{s})}+\mathrm{O}_{2(\mathrm{~g})} \rightarrow \mathrm{Fe}_{2} \mathrm{O}_{(\mathrm{s})}$

Transient iron (i)oxide

- $2 \mathrm{Fe}_{2} \mathrm{O}_{(\mathrm{s})}+\mathrm{O}_{2(\mathrm{~g})} \rightarrow 4 \mathrm{FeO}_{(\mathrm{s})}$

- $6 \mathrm{FeO}_{(\mathrm{s})}+\mathrm{O}_{2(\mathrm{~g})} \rightarrow 6 \mathrm{Fe}_{2} \mathrm{O}_{3}$

- $\quad 4 \mathrm{Fe}_{3} \mathrm{O}_{4(\mathrm{~s})}+\mathrm{O}_{2(\mathrm{~g})} \rightarrow 6 \mathrm{Fe}_{2} \mathrm{O}_{3(\mathrm{~s})}$

As the temperature of the igneous rock continues to drop with $\Delta \mathrm{G}<0$, the ferrimagnetic minerals become richer in titanium. At this temperature, the numbers of atoms of titanium replace equal atoms of the iron in the solid solution as shown in Table 2. This continues so that at about $600^{\circ} \mathrm{C}$, there is complete solid-solution between magnetite and ulvospinel with $\Delta \mathrm{G}>0$ and this is known as Titanization reaction of iron ore as shown in equation (6) below.

$$
600^{\circ} \mathrm{C}
$$

$2 \mathrm{Fe}_{3} \mathrm{O}_{4(\mathrm{~s})}+2 \mathrm{TiO}_{2(\mathrm{~s})} \rightarrow 2 \mathrm{Fe}_{2} \mathrm{TiO}_{4(\mathrm{~s})}+2 \mathrm{FeO}_{(\mathrm{s})}+\mathrm{O}_{2(\mathrm{~g}), \Delta \mathrm{G}>0}$

And above about $800^{\circ} \mathrm{C}$, there is a complete solid-solution between haematite and ilmenite with DG>0 as shown in equation (7) below and is also called Titanization reaction series of iron ore.

$$
800^{\circ} \mathrm{C}
$$

$2 \mathrm{Fe}_{2} \mathrm{O}_{3(\mathrm{~s})}+2 \mathrm{TiO}_{2(\mathrm{~s})} \rightarrow+2 \mathrm{FeTiO}_{3(\mathrm{~s})}+\mathrm{O}_{2(\mathrm{~g}), \Delta \mathrm{G}>0}$

$\Delta$

The iron oxide, $\left(\mathrm{Fe}_{2} \mathrm{O}_{3}\right)$, which is stable at above temperature of about $800^{\circ} \mathrm{C}$ reacts in unison with titanium oxide to produce a pseudo mineral called pseudo brookite $\left[\mathrm{Fe}_{2} \mathrm{TiO}_{5}\right]$ as shown in equation (8) below.

- $\mathrm{Fe}_{2} \mathrm{O}_{3(\mathrm{~s})} \stackrel{\mathrm{TiO}_{3}}{\longrightarrow} \quad \mathrm{Fe}_{2} \mathrm{TiO}_{5(\mathrm{~s})}$

Titanium replaces iron in equal proportion as the temperature of the rock continues to drop. This process continues so that at about above a temperature of $800^{\circ} \mathrm{c}$, there is a complete solid-solution between pseudobrookite, and ilmeno rutile as shown in equation (9) below.

$$
\text { - } \mathrm{FeTiO}_{3(\mathrm{~s})} \stackrel{\mathrm{TiO}_{2(3)}}{\longrightarrow} \mathrm{FeTi}_{2} \mathrm{O}_{5(3)} \ldots \ldots \ldots . . . .(9)
$$




\subsection{Mathematical Expression for Iron Ore}

At rhyolitic and basaltic melt temperatures, magmas behave like weak electrolyte, especially on a microscopic scale and are applicable to principle of electroneutrality (Denbigh, 1971). Titanium is a trace for igneous rock, because it precipitates at igneous temperature. At an igneous temperature, there is a mobility of ions or atoms in the magma solution, since it behaves like a weak electrolyte under electrolytic condition according to Faraday second law of electrolysis, within the magma, such that under control condition of temperature, ions or atoms of the same charge or similar size must find themselves and occupy a lattice position to form crystals (Goldschmidt, 1937), which set in matrix (Cayley, 1895), to form rock of a particular composition. The rock formed would reduce to an ore whenever there is a weathering breakdown, such that high temperature minerals are more susceptible to weathering breakdown and would have gone into solution leaving behind low temperature minerals (Goldich 1988). Since titanium crystalizes at an igneous temperature, with respect to iron under electrolytic condition, there is always a solid solution between titanium and iron and can be mathematically expressed in the following equations below

Mathematical derivations of iron ores are based on charge balance of the constituent species, according to Denbigh, (1971), which states that, the principle of electro neutrality requires that the ionic species in an electrolyte solution remains charge balanced on a microscopic scale. The electro neutrality condition of charge balanced among the species in solution, according to equation (11).

$\sum \mathrm{Z}_{\mathrm{i}} \mathrm{M}_{\mathrm{i}}+\sum \mathrm{Z}_{\mathrm{j}} \mathrm{M}_{\mathrm{j}}=0$

Where $Z_{i}$ and $Z_{j}$ are the ionic charges on basis and secondary species. It is useful to note, however, that electroneutrality as assured when the components in the basis are charge balanced.

Because at an igneous temperature condition, magma behaves like a weak electrolyte on a microscopic scale, application of Denbigh equation is necessary to solve the problem of rock forming ores and is expressed as follows;

- Oxygen (0) is a single anion with unit charge of $(-2)$.

$0=-2$

$=0^{2-}$

- Cation with equivalent unit positive charge is needed to balance it, so that the algebraic sum is equal to zero.

- Let the cation be $\left(\mathrm{X}^{+2}\right)$ so that the formula becomes

$\mathrm{n}\left[\left(\mathrm{x}^{+2}\right)\left(\mathrm{O}^{-2}\right)\right]=\mathrm{nXO}$

From equation (12), more electropositive element $\mathrm{Y}$ will replace some atoms of $\mathrm{X}$ in equal proportion so that the equation becomes

$\mathrm{nXO}=\mathrm{X}_{1-\mathrm{x}} \mathrm{Y}_{\mathrm{x}} \mathrm{O}$

As temperature drops, there is an oxidation of $\mathrm{nXO}$ as shown equation 14.

$\mathrm{nXO}_{(\mathrm{s})} \stackrel{n[\mathrm{O}]}{\longrightarrow} \mathrm{nX}_{3} \mathrm{O}_{4(\mathrm{~s})}$

$\mathrm{n}\left[\mathrm{X}_{1-\mathrm{x}} \mathrm{Y}_{\mathrm{x}}\right] \mathrm{O} \stackrel{n[\mathrm{O}]}{\longrightarrow} \mathrm{n}\left[\mathrm{X}_{3-\mathrm{x}} \mathrm{Y}_{\mathrm{x}}\right] \mathrm{O}_{4}$

..(14): Oxidation

Equation (15) is used to calculate titano magnetite series as shown in Table 2.

The oxidation of equation $\mathrm{nX}_{3} \mathrm{O}_{4}$ will give more stable crystal as shown equation (16).

$$
\begin{aligned}
& \mathrm{nX}_{3} \mathrm{O}_{4(\mathrm{~s})} \stackrel{n[O]}{\longrightarrow} \mathrm{nX}_{2} \mathrm{O}_{3(\mathrm{~s})} \ldots \ldots \ldots . . . .(16): \text { Oxidation } \\
& \text { haematite } \\
& \mathrm{n}\left[\mathrm{X}_{3-\mathrm{x}} \mathrm{Y}_{\mathrm{x}}\right] \mathrm{O}_{4} \stackrel{n[O]}{\longrightarrow} \mathrm{n}\left[\mathrm{X}_{2-\mathrm{x}} \mathrm{Y}_{\mathrm{x}}\right] \mathrm{O}_{3} \ldots(17): \text { Titanization }
\end{aligned}
$$

Equation (17) is used to calculate titano - haematite series shown in Table 2.

\subsection{Sequence of Crystallization of Iron Ore using Mathematical Expressions with Respect to Gibb's free Energy $(\Delta G)$}

According to second law of thermodynamic, for systems reacting at standard conditions for temperature and pressure, there is a general natural tendency to achieve a minimum of the Gibbs free energy (Gibbs, 1873).

Geomathematically, during cooling of magma, the first magnetic mineral to form is said to be in the state of chemical equilibrium with the melt, provided that temperature and pressure are kept constant, according to Gibbs (1873), numerically, $\Delta G=0$. But with change in the condition of temperature under isobaric condition imposed on the system in a state of chemical equilibrium, free Gibbs energy will be negative (numerically, $\Delta \mathrm{G}<0$ ), so that the reaction would be spontaneous and equilibrium will shift to the point that favours crystallization, so as to annul the cooling effect by releasing more heat, according to Le-chaterlier principle (1898) as a result, the first magnetic mineral to form oxidizes into another magnetic mineral, that is structurally different with distinct chemical composition. This process is called oxidation reaction in this research and the reaction is discontinuous, because oxygen is the only factor that determines the reaction, with less or no substitution of iron by titanium.

After oxidation, the surviving magnetic mineral would undergo series of reactions by substitutions of elements by another to produce crystals of the same structures, but with different chemical compositions, with free Gibbs energy, numerically less than zero $(\Delta G<0)$, but if the temperature imposed on the system remains the same, the crystals produced, would be at equilibrium with free minimum Gibb's energy, numerically, $\Delta \mathrm{G}>0$. This process is called solid solution and the reaction is Titanization reaction and is continuous because titanium is only factor that determines the reaction as shown in Table 2 . 
Geomathematically, as a result of these, two series of reactions are attributed to mathematical models of iron ore; hence, Oxidation reaction series called the Magneto- Haematite series and the Titanization series called Titano - Magneto Haematie series as shown in Table 2

Oxidation reactions series are series of equations that are discontinuous during cooling of magma and are required controlled addition of oxygen, to an already existing crystal that crystalizes from the melt, to form another crystal of different structure, but with distinct chemical composition and are called Magneto -Haematite series.

This progresses in sequence as temperature drops to produce sequence of crystallization with respect to free Gibbs energy $(\Delta \mathrm{G})$ and is given below in order of increasing oxygen content.

$$
\begin{array}{ccc}
{\left[X_{1}\right] O} & \rightarrow\left[X_{3}\right] O_{4} \rightarrow\left[X_{2}\right] O_{3} \\
\Delta G=0 & \Delta G=0 \quad \Delta G=0 \\
& \text { Wustite } \rightarrow \text { Magnetite } \rightarrow \text { Haematite }
\end{array}
$$

Solid solution equations are series of equations that are continuous and they involve substitutions among the cations called (ionic substitution), to produce crystal of same structure but with different chemical compositions. Example, Titanium substitutes for iron in solid solution to form crystals that are intermediates in which both Titanium and iron are present in equal proportion. Therefore, for intermediate, the following sequence is formed and is called Tiatano Magnetite.

$$
\begin{array}{rccc}
{\left[X_{1-x} Y_{x}\right] O} & & {\left[X_{3-x} Y_{x}\right] O_{4}} & {\left[X_{2-x} Y_{x}\right] O_{3}} \\
\Delta G<0, & \rightarrow & \Delta G<0 & \Delta G<0
\end{array}
$$

Titano - Wustite $\rightarrow$ Titano-magnetite $\rightarrow$ Titano-Haematite $\rightarrow$

The complete or partial substitution of Iron by Titanium would produce crystals that are wholly or partially Titanium and are feebly magnetic, because they are stable in the presence of free titanium with minimum free Gibbs energy, numerically $\mathrm{DG}>0$ and are represented sequentially bellow

$$
\begin{aligned}
& {\left[X_{1-x} Y_{x}\right] O \quad\left[X_{3-x} Y_{x}\right] O_{4} \quad\left[X_{2-x} Y_{x}\right] O_{3}} \\
& \Delta G>0, \quad \rightarrow \quad \Delta G>0 \quad \Delta G>0 \\
& \text { Rutile } \rightarrow \text { Ulvospinel } \rightarrow \text { Ilmenite }
\end{aligned}
$$

These minerals are formed sequentially to produce rocks of different compositions. Basalt is an igneous rock which mathematically and mineralogically consists of wustite, magnetite, haematite, depending on temperature of crystallization.

The probability of having any of these minerals in basalt depends on factor of temperature. The following minerals are presented sequentially bellow.

$$
\begin{aligned}
& {\left[\mathrm{X}_{1} \mathrm{O}\right]+\left[\mathrm{X}_{3} \mathrm{O}_{4}\right]+\left[\mathrm{X}_{2} \mathrm{O}_{3}\right]=\left[\left[\mathrm{X}_{3} \mathrm{O}_{4}\right] \mathrm{X}_{2} \mathrm{O}_{3}\right]} \\
& \text { Wustite }+ \text { Magnetite }+ \text { Ilmenite }=\text { Basalt } \Delta G=0 \\
& {\left[X_{1-x} Y_{x}\right] \mathrm{O}+\left[X_{3-x} Y_{x}\right] O_{4}+\left[X_{2-x} Y_{x}\right] O_{3}=\begin{array}{c}
{\left[X_{3-x} Y_{x}\right] O_{4}\left[X_{2-x} Y_{x}\right] O_{3}} \\
\Delta G<0
\end{array}}
\end{aligned}
$$

Titano - wustite + Tiatano - Magnetite + Titano - haemite $=$ Andesite

$$
\begin{array}{cccc}
{\left[X_{1-x} Y_{x}\right] O} & +\left[X_{3-x} Y_{x}\right] O_{4}+\left[X_{2-x} Y_{x}\right] O_{3}= & {\left[X_{3-x} Y_{x}\right] O_{4}\left[X_{2-x} Y_{x}\right] O_{3}} \\
\text { Wustite } & +\quad \text { ULvospel } & \Delta \text { Ilmenite } & =\text { Rhylite }
\end{array}
$$

Sequentially, we have the rocks arranged in the following ways using mathematical equations;

$$
\begin{array}{ccc}
{\left[X_{3} O_{4}\right]\left[X_{2} O_{3}\right] \stackrel{900^{\circ} \mathrm{C}}{\longrightarrow}\left[X_{3-x} Y_{x}\right] O_{4}\left[X_{2-x} Y_{x}\right] O_{3}} & \stackrel{650^{\circ} \mathrm{C}}{\longrightarrow}\left[X_{3-x} Y_{x}\right] O_{4}\left[X_{2-x} Y_{x}\right] O_{3} \\
\Delta G=0 & \Delta G<0 & \Delta G>0 \\
\text { Basalt } & \text { Andesite } & \text { Rhyolite }
\end{array}
$$

\section{Research Methodology}

Samples of fresh iron ores were obtained from Itakpe iron ore deposit, using random sampling method and cassiterite from Jos Plateau state. The samples of Itakpe iron ore deposit were collected at various spots, $5 \mathrm{~m}$ apart. $20 \mathrm{~kg}$ of cassiterite sample was obtained for the study. The sample of cassiterite was taken and broken manually with a sledge hammer to provide the required size acceptable to laboratory jaw crusher. The samples were crushed and pulverized, part of pulverized samples was weighed for sieve analysis and processing using magnetic separator. The procedure is as follows.

- $1 \mathrm{~kg}$ each of raw sample of Itakpe iron ore and $20 \mathrm{~kg}$ of cassiterite were crushed and pulverized in the laboratory mill machine for an hour,

- The sample of Itakpe iron ore and cassiterite were taken and sized by sieving into a number of size fraction using the automatic sieve shaker for 15 minutes.

- The "Itakpe iron ore" and cassiterite were each gathered together and introduced into the laboratory mill machine and ground for 15 minutes.

- $\quad$ The Itakpe iron and the cassiterite from the laboratory ball mill machine were sized and each sieve fractions were weighed and the value noted as the product or discharge.

- $\quad$ Sieve analysis. The ground samples were sieved into the following sieve size fractions; $+365 \mu \mathrm{m}, 355 \mu \mathrm{m},+250$ $\mu \mathrm{m},-250 \mu \mathrm{m},+180 \mu \mathrm{m},-180 \mu \mathrm{m},+125 \mu \mathrm{m},-125 \mu \mathrm{m},+90 \mu \mathrm{m},-90 \mu \mathrm{m},+63 \mu \mathrm{m},-63 \mu \mathrm{m}$ using automatic sieve shaker for 15 minutes. 
- The discharged product of cassiterite was taken to magnetic separator for processing.

- Ordinary bar magnet of about 0.01 Tesla which produces 650 magnetic field lines is used to measure the magnetic property of the iron ores obtained from the sources, that is, itakpe iron ore and cassiterite from Jos plateau state

- Relative densities of each of the minerals from both pulverized Itakpe iron ore and the processed cassiterite were measured using Archimedes' principle and their specific gravities were calculated.

\section{Expected Results and Discussion}

\subsection{Expected Results}

The expected values measured from magnetization, strength, density and matrix equations according to titanium to iron ratio using Archimedes' principle, Magnet and Triaxia testing machine are presented in Table 1

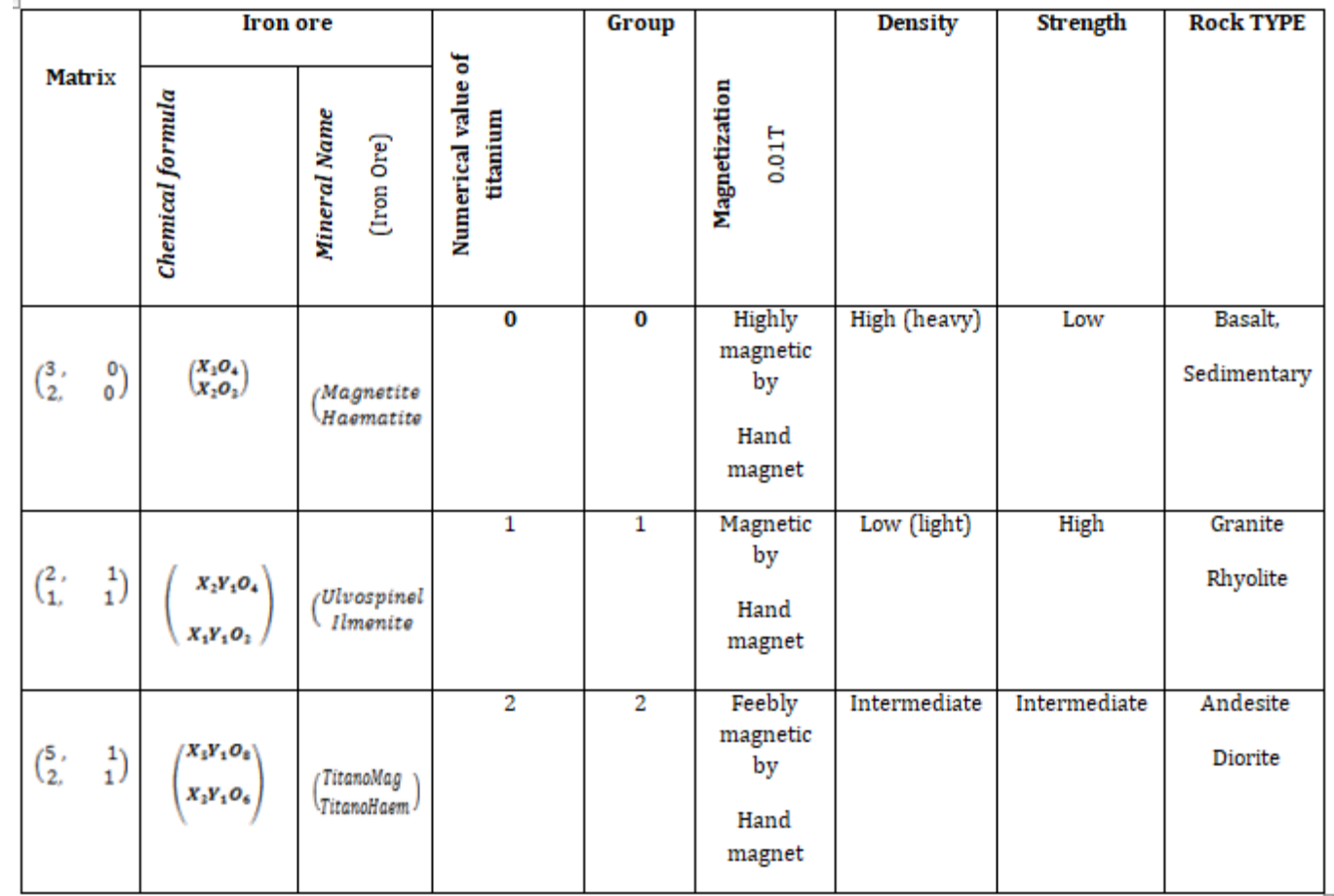

Table 1: Expected Values Measured from Magnetization, Density and Strength

\subsubsection{Mathematical Modeling of Iron Ore}

Consider that, iron ore is a product of sedimentary rock and a weathering product of igneous rock, given that titanium is a distinguishing factor between sedimentary and igneous rocks, therefore;

- Under sedimentary condition, there is no titanium, with $0<\Delta \mathrm{G}<0$

- Under igneous condition, titanium is present with $0<\Delta \mathrm{G} \leq 0$

Based on these two assumptions, matrix equation is used to resolve the problem between iron ore in sedimentary and iron ore in igneous rocks and the equations are mathematically expressed below;

From equation 6, $n\left[X_{3-x} Y_{x}\right] O_{4} \stackrel{n[O]}{\longrightarrow} n\left[X_{2-x} Y_{x}\right] O_{3}$, we have that;

$$
\begin{array}{r}
{\left[X_{3-x} Y_{x}\right] O_{4}=0, \text { where }} \\
3-x=x \text { position } \\
x=y \text { position }
\end{array}
$$

Using factor theorem,

$$
\text { At } x=0
$$

$\left[X_{3-x} Y_{X}\right] O_{4}=\left[X_{3}\right] O_{4}$

Such that, $3-x=x$ position

3- $0=3$

$x=3$, and

$x=y$ position;

$0=y$

$y=0$

$[x, y][3,0]=\left[X_{3}\right] O_{4}$

At $x=1$

$\left[X_{3-x} Y_{x}\right] O_{4}=\left[X_{2} Y_{1}\right] O_{4}$, such that,

$3-x=x$ position

$3-1=x$

$x=2$ and

$x=y$ position 
$1=y$

$y=1$

$[x, y][2,1]=\left[X_{2} Y_{1}\right] O_{4}$

$\left[X_{3}\right] O_{4(s)}+\left[X_{2} Y_{1}\right] O_{4}=[3,0]+[2,1] \ldots$

Also $\left[X_{2-x} Y_{X}\right] O_{3}=0$, where;

$2-x=x$ position

$x=y$ position

Using factor theorem,

At $x=0$

$\left[X_{2-x} Y_{x}\right] O_{3,}=\left[X_{2}\right] O_{3,}$.

Such that $2-x=x$ position

$2-0=x$

$\left[X_{2} Y_{1}\right] O_{4} \quad x=y$ position

$0=y$

$Y=0$

$[x, y][2,0]=\left[X_{2}\right] O_{3}$

At $x=1$

$\left[X_{2-x} Y_{x}\right] O_{3,}=\left[X_{1} Y_{1}\right] O_{3}$

Such that, $2-X=x$ position

$2-1=x$

$x=1$ and

$x=y$ position

$1=y$

$Y=1$

$[x, y],[1,1]=\left[X_{1} Y_{1}\right] O_{3} \ldots \ldots . .(25)$

$\left[X_{2}\right] 0_{3}+\left[X_{1} Y_{1}\right] O_{3}=[2,0]+[1,1] \ldots \ldots(26)$

$\left[X_{3}\right] O_{4}+\left[X_{2} Y_{1}\right] O_{4}=\left[X_{5} Y_{1}\right] O_{8} \ldots . . .(27)$

$\left[X_{2}\right] O_{3}+\left[X_{1} Y_{1}\right] O_{3}=\left[X_{3} Y_{1}\right] O_{6} \ldots . . .(28)$

Using matrices method, to represent numerical values assigned to chemical elements in its algebraic form to produce iron ore of a particular IUPAC nomenclature, we have;

$$
\begin{aligned}
& \left(\begin{array}{ll}
3, & 0 \\
2, & 0
\end{array}\right)+\left(\begin{array}{l}
2,1 \\
1,1
\end{array}\right)=\left(\begin{array}{c}
5,1 \\
3,1
\end{array}\right) \ldots \ldots \ldots(29) . \\
& \left(\begin{array}{l}
X_{3} O_{4} \\
X_{2} O_{3}
\end{array}\right)+\left(\begin{array}{c}
X_{2} Y_{1} O_{4} \\
X_{1} Y_{1} O_{3}
\end{array}\right)=\left(\begin{array}{c}
X_{5} Y_{1} O_{8} \\
X_{3} Y_{1} O_{6}
\end{array}\right) \ldots \ldots(30) \\
& \left(\begin{array}{c}
\text { Magnetite } \\
\text { Haematite }
\end{array}\right)+\left(\begin{array}{c}
\text { Ulvospinel } \\
\text { Ilmenite }
\end{array}\right)=\left(\begin{array}{c}
\text { Titanomagnetite } \\
\text { Titanohaematite }
\end{array}\right) \text {. }
\end{aligned}
$$

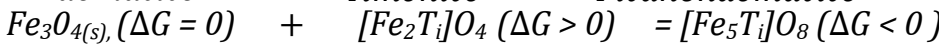

$$
\begin{aligned}
& {\left[\mathrm{Fe}_{2}\right] \mathrm{O}_{3(\mathrm{~s})}(\Delta \mathrm{G}=0)+\left[\mathrm{FeT}_{i}\right] \mathrm{O}_{3}(\Delta G>0)=\left[\mathrm{Fe}_{3} \mathrm{~T}_{i}\right] \mathrm{O}_{6}(\Delta G<0) \ldots . . .(33)} \\
& [\text { Basalt, } \Delta G=0]+\text { [Granite, } \Delta G>0]=[\text { Andesite, } \Delta G<0] \ldots . . . \text { (34) }
\end{aligned}
$$

[Sedimentary, $0<\Delta G<0]+[$ Granite $\Delta G>0]=[$ Andesite $\Delta G<0] \ldots . . .(35)$

From equations (34) and (35), it means that weathering of basalt will give magnetite and haematite, that of granite will give ulvospinel and ilmenite, and that of andesite will give titanomagnetite and titanohaematite.

Equations (33) and (34) indicate that granite and andesite are trace for titanium and it affects the magnetization, strength and density of iron ores as shown in table 3

$\left[\mathrm{Fe}_{3}\right] 0_{4}$, with $\Delta \mathrm{G}=0$, responds quickly to magnetism by stationary hand magnet which indicates the absence of titanium in magnetite and is mainly sedimentary as well as perridotite and dunite and even some basalt.

$\left[\mathrm{FeT}_{\mathrm{i}}\right] \mathrm{O}_{3}$, with $\Delta \mathrm{G}>0$ feebly responds to magnetism by rotating hand magnet, with the density less than the magnetite and a greater tensile strength, which indicates the presence of titanium and is mainly igneous like granite. This means, the presence of titanium in granite affects the properties of iron ores such as magnetization, strength and density and the amount of titanium in iron ore increased from Basic e.g., basalt with free Gibbs, not minimum numerically, $\Delta \mathrm{G}=0$ to more Acidic e.g., granite with free minimum energy, numerically $\Delta \mathrm{G}>0$, which gives the account that oceanic basalt is more magnetic, more dense, weaker strength and less stable than the continental granite.

Continental granite has a free Gibbs energy that is minimum, numerically greater $(\Delta \mathrm{G}>0)$ and that of basalt has its free Gibbs energy but not minimum, numerically less than zero $(\Delta \mathrm{G}<0)$. Because of this, continental granite is generally more stable than oceanic basalt.

5.1.2. Using Determinant Matrix to Classify Iron Ore into Groups

$$
\text { Using determinant matrix to resolve equation (29) into equation (36) }
$$

$\left(\begin{array}{ll}3, & 0 \\ 2, & 0\end{array}\right)+\left(\begin{array}{l}2,1 \\ 1,1\end{array}\right)=\left(\begin{array}{c}5,1 \\ 3,1\end{array}\right)$

$[0]+[1]=[2]$

Therefore; 


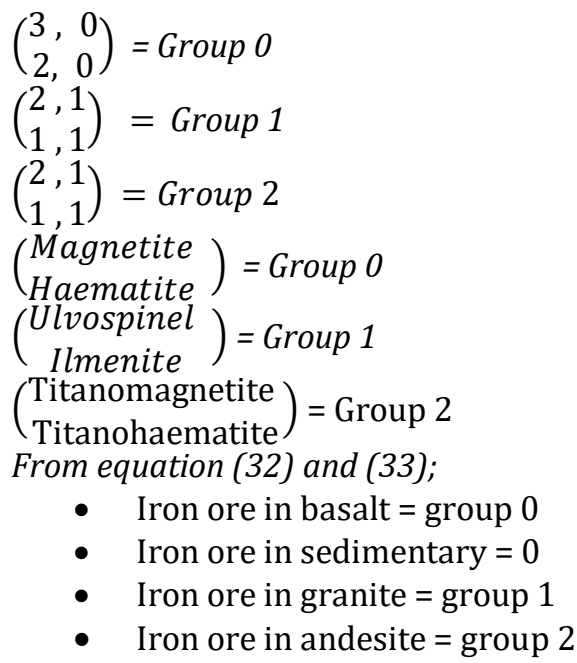

\subsection{Discussion of Results}

\subsubsection{Iron Ore Model}

Geomathematically, for an ore to be called an iron ore, it must contain a minimum of 1 to $5 \%$ of iron ore. Several experiments have shown that, in cassiterite ore, the maximum concentration of iron ore in cassiterite is $23.75 \%$ in composition and that of titanium oxide is $16.7 \%$ in composition. Other magnetic minerals occur in trace. While in Itakpe iron ore, the maximum concentration of iron ore in the ore is $27.1 \%$ in composition in which titanium oxide occurs as trace, about 0.79 in composition or in many cases absent. The presence of titanium oxide in cassiterite after chemical analysis indicates that there is always solid solution between titanium and iron at igneous temperature in form of $\mathrm{Fe}_{2} \mathrm{O}_{3} / \mathrm{TiO}_{2}$. This means that titanium forms at igneous temperature at about $600^{\circ} \mathrm{C}$ to $1100^{\circ} \mathrm{C}$. In Itakpe iron ore, the total absent or little amount of titanium indicates that there is no solid solution (exsolution) between titanium and iron in the ore at sedimentary temperature, because the temperature requires for titanium to precipitate from the melt is far above sedimentary temperature, unless the sedimentary material is heated up to igneous temperature that would precipitate titanium from the melt. Based on this, periodic table has been designed to classify iron ore into group according to titanium to iron ratio with respect to free Gibbs energy $(\Delta \mathrm{G})$ called Periodic Table of iron ore as shown in Table 3 . Based on titanium to iron ratio, Itakpe iron ore is placed in group zero (0) iron ore type, while iron ore from cassterite is placed in group one and two (1 and 2) iron ore type.

From Table 2, wustite crystallizes first with free energy, numerically less than zero $(\Delta G<0)$, and then with time and decreasing temperature, it oxidizes to magnetite, with free energy numerically equal to zero $(\Delta \mathrm{G}=0)$ and hematite, with free energy numerically greater than zero $(\Delta G>0)$ called oxidation reaction series as you are going across the table from left to right. As you are going down the table from top to bottom, the number of atoms of iron decreases with increasing number of atoms of titanium. The general molecular formulas for the two series of solid solutions are $\left[X_{3-x} Y_{X}\right] O_{4}$ for Titanomagnetite series and $\left[X_{2-x} Y_{x}\right] O_{3}$ for Titanohaematite series, as $\mathrm{x}$ ranges from 0 to 1 ; the following minerals are obtained, and are subjected to a hand magnet of about $0.01 T$, tensile strength and measurement of density. These minerals are, Wustite, Magnetite, Haematite, Pseudo Brookite, Rutile, Ulvospinel, Ilmenite,

Table 2, indicates that iron rich zone contains rock types such as basalt, dolerite, gabbro with a general free Gibbs energy but not minimum, numerically $\Delta \mathrm{G}=0$ and the titanium rich zone contains rock types such as granite, rhyolite and diorite pegmatite with a general minimum free Gibbs energy numerically, $\Delta G>0$.

The minerals in the upper part of Table 2, such as magnetite and haematite, are high density minerals, because iron, which is a transition element placed in group VB, period four, has a density of 4.5, according Mendeleev (1902). This makes rocks rich in iron, heavy and is ferrimagnetic at room temperature because of its opposite and unequal spins magnetic moment, which is strongly magnetic when placed in magnetic field of about $0.01 T$, as shown in table 3 and as such used in heavy duty machines for vehicles, and giant magnet for electronics and transformers. The minerals in the lower part of Table 2 such as ulvospinel and ilmenite are hard, lustrous, and low-density minerals, because of partially replacement of iron by titanium in the solid solution which has a density lower than that of iron. Because of its light in weight to density ratio, hard, lustrous, as well as rust resistance, it is used as a construction material for aircraft parts, artificial joints for humans and sporting equipment such as bicycle frames. It is anti-ferromagnetic, at a low temperature, and paramagnetic at room temperature.

The minerals in the upper part of Table 2, such as magnetite and haematite, are high density minerals, because iron, which is a transition element placed in group VB, period four, has a density of 4.5, according to Mendeleev (1902). This makes rocks rich in iron, heavy and is ferrimagnetic at room temperature because of its opposite and unequal spins magnetic moment, which is strongly magnetic when placed in magnetic field of about $0.01 T$, as shown in table 2 and as such used in heavy duty machines for vehicles, and giant magnet for electronics and transformers. The minerals in the lower part of Table 2 such as ulvospinel and ilmenite are hard, lustrous, and low-density minerals, because of partially replacement of iron by titanium in the solid solution which has a density lower than that of iron. Because of its light in weight to density ratio, hard, lustrous, as well as rust resistance, it is used as a construction material for aircraft parts, 
artificial joints for humans and sporting equipment such as bicycle frames. It is anti-ferrimagnetic, at a low temperature, and paramagnetic at room temperature.

\subsubsection{Periodic Table of an Iron Ore}

Determinant matrix is used to construct Periodic Table of an iron ore according to titanium to iron ratio with respect to magnetization, strength and density in which titanium is determinant factor and iron is a constant variable and is expressed as follows from equations (29) and (36)

$$
\begin{gathered}
\left(\begin{array}{l}
3,0 \\
2,0
\end{array}\right)+\left(\begin{array}{l}
2,1 \\
1,1
\end{array}\right)=\left(\begin{array}{l}
5,1 \\
3,1
\end{array}\right) \\
{[0]+[1]=[2]}
\end{gathered}
$$

Table 1, shows that iron-titano-oxide is grouped into three according to the ratio of iron to titanium, based on this research. These are group 0 , group 1 , and group 2 .

- Group 0: In this group, the amount of titanium is zero, and iron ion increases from +2 with a general minimum energy numerically $\Delta \mathrm{G}<0$ to +3 with a general minimum energy numerically $\Delta \mathrm{G}=0$ and has not been affected by titanium. Minerals in this group are highly magnetic and high density and first weathered under weathering condition, Goldich (1988).

- Group 1: This group is divided into sub-groups such as $A_{i}, A_{2}$, and $A_{3}$ and has been affected by titanium. In this group, the amount of titanium atom increases down the group with decreasing number of atoms of iron by one (1), making it group one. Across the group from left to right, titanium atom is constant, with increasing magnetization and densities, but down the group, magnetization and densities decrease.

- Group 2: This is divided into subgroups such as $B_{1}, B_{2}$ and $B_{3}$, in this group, the amount of titanium atom increases down the group with decreasing number of atoms of iron by two (2), making it group 2 mineral. Across the group, from $B_{1}$ to $B_{3}$, titanium atom is constant, with increasing magnetization and densities, but down the group,

\begin{tabular}{|c|c|c|c|}
\hline UP & 0 & 1 & 2 \\
\hline & \multirow[t]{2}{*}{$\begin{array}{l}\text { The amount } \\
\text { of titanium }\end{array}$} & $\begin{array}{l}\text { Down the vertial column, Titanium } \\
\text { displaces iron by one atom. } \\
\text { - Down the vertical column, iron } \\
\text { atom decreases with increasing } \\
\text { number of Titanium atom. }\end{array}$ & $\begin{array}{l}\text { Down the vertial column, Titanium atom } \\
\text { displaces Iron atom by two. } \\
\text { Down the vertical column, Iro n atoms } \\
\text { decrease with increasing Titani um atom } \\
\text { by two. }\end{array}$ \\
\hline & & $\mathrm{A} 2$ & B3 \\
\hline & $\mathrm{FeO}$ & Fe.TiO Fe TiO Fe TiO & $\mathrm{Fe}, \mathrm{TiO}_{0} \mathrm{Fe}$ sTiO॰ $\mathrm{Fe}$ JiO \\
\hline & $\mathrm{Fe} \mathrm{O}$ & $\mathrm{Fe}, \mathrm{Ti}_{2} \mathrm{O}_{5} \mathrm{Fe}_{0} \mathrm{Ti}_{2} \mathrm{O}_{2} \quad \mathrm{Fe} \mathrm{Ti}_{2} \mathrm{O}_{5}$ & $\mathrm{Fe}, \mathrm{Ti}_{3} \mathrm{O}_{10} \mathrm{Fe}_{z} \mathrm{Ti}_{3} \mathrm{O}_{\infty} \quad \mathrm{Fe}{ }_{\pi} \mathrm{Ti}_{3} \mathrm{O}_{3}$ \\
\hline & $\mathrm{FeO}$ & $\mathrm{Fe}=\mathrm{Ti}_{3} \mathrm{O}_{5} \mathrm{Fe}=\mathrm{Ti} \mathrm{O}_{2} \mathrm{Fe}$, Ti $\mathrm{O}_{\text {is }}$ & $\mathrm{Fe}_{5} \mathrm{Ti}_{5} \mathrm{O}_{10} \mathrm{Fe} \approx \mathrm{TiO} \mathrm{C}_{0} \mathrm{Fe}{ }_{5} \mathrm{Ti}_{5} \mathrm{O}_{\infty}$ \\
\hline & TiO & $\mathrm{Fe}$ Ti. $\mathrm{O}_{3} \mathrm{Fe}$ "Ti. $\mathrm{O}_{\infty} \mathrm{Fe}$.Ti.$_{\infty}$ & 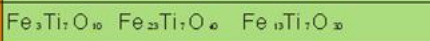 \\
\hline & & & $\mathrm{Fe}_{3} \mathrm{Ti}_{0} \mathrm{O}_{0} \mathrm{Fe} e_{21} \mathrm{Ti}_{2} \mathrm{O}$ 。 $\mathrm{Fe}{ }_{11} \mathrm{Ti}_{2} \mathrm{O}_{0}$ \\
\hline
\end{tabular}
magnetization and densities decrease.

Figure 2: Periodic Table of Iron According to Their Groups on the Basais of Their Cemical Beheviour

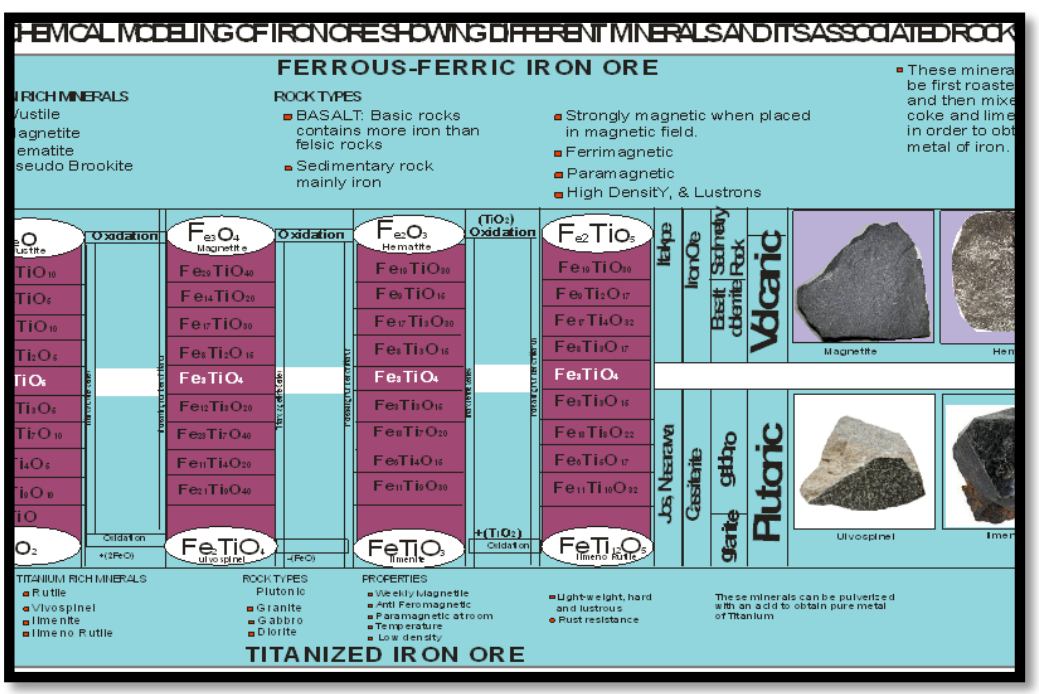

Figure 3: Mathematical and Chemical Modeling of Iron Ore Showing Different Minerals and Its Associated Rocks

\section{Summary of Findings}

The effect of titanium on iron ore can be summarized in the following ways;

- The amount of titanium in the silicate melt depends on the amount of water in the silicate melt. This means that as the amount of water increases in the melt, the amount of titanium also increases. 
- Drop in temperature in the melt, increases the water content of the melt. This means that water depresses the crystallization of anhydrous melt and increases the crystallization of a hydrous melt such as amphibole and mica. For this reason, the concentration off titanium is more in hydrous melt than in the anhydrous melt since water controls the concentration of titanium in the melt.

- There is an exsolution in the hydrous melt, because of presence of titanium; therefore, there is ionic substitution of iron by titanium in the melt during solid solution.

- There is no exsolution in anhydrous melt, likewise the sedimentary rock, because the condition that favours the concentration of titanium is limited in the melt.

- From Table 2, there is an arithmetic progression of titanium as you go from the top to bottom of the Table. This means there is a successive increment of titanium and decrement of iron from the top to bottom of the table.

- The increment of titanium and decrement of iron from top to bottom affect the properties of iron ore such its composition, its magnetism and the strength as well as its density.

- The effect of titanium in an iron ore can be mathematically summarized through the following equation at the root of the equation $[0,1]$.

1

$\Sigma\left(X_{1-x} Y_{X}\right) O,\left(X_{3-X} Y_{X}\right) O_{4},\left(X_{2-X} Y_{X}\right) O_{3,}=0$, at the point of $(0,1)$.

$x=0$

If the summation of the equation is equal to zero and $x=0$, then the iron ores produced are magnetite, haematite and wustite this is called ferrous-ferric iron ore with the associated rock types such as basalt and sedimentary rock. But at $\mathrm{x}=1$, the iron ores are titanized iron ore called titanization. They include ilmenite, ulvospinel, rutile and pseudobroockite with the associated rocks such as granite and gabbro

\section{Conclusion}

Using mathematical modeling approach to appraise the effect of titanium on iron ore, it could be concluded that the presence of titanium in an iron ore decreases the magnetic property, density, with increment in the cell size and high tensile strength of iron ore. The grade of iron ore is determined by more or less amount of titanium it contains. Findings have shown that, the high magnetization by ordinary hand magnet, with low strength and greater density of Itakpe iron ores indicate that the ores have not been affected by titanium as haematite-magnetite series and the rock origin is sedimentary with a general minimum energy numerically $\Delta \mathrm{G}=0$, because of this; the iron ore is concentrated in low magnetic intensity separator and ferrimagnetic at room temperature at 1atm. Conversely, the low magnetization by hand magnet with greater strength and lower density indicate that the ores from Cassiterite have been affected by titanium as ilmeno-ulvospinel series and the rock origin is granite with a general minimum energy numerically $\Delta \mathrm{G}>0$ and andesite with a general minimum energy numerically $\Delta \mathrm{G}<0$, because of this, the iron ore is concentrated in high magnetic intensity separator and paramagnetic at room temperature at 1atm. Finally, the presence or absence of titanium in an iron ore determines the types of magnetic separators used to separate the ores from the gangue, as well as their genetic rock origin, in which the amount of titanium in iron ore increases from Basic e.g., basalt to more Acidic e.g., granite which gives the account that oceanic basalt is more magnetic, more dense, weaker strength and less stable than the continental granite.

Additionally, using matrix methods from equations (19), (20) and (21), iron ores from Itakpe and cassiterite were modeled in which titanium is a determinant factor, and periodic table was designed to classify them into groups.

\section{Innovation/Contribution to Knowledge}

After comparative analyses between Itakpe iron ores and cassiterite in Jos Plateau state, using magnetism, strength, and density to appraise the iron ores according to titanium to iron ratio, an expected concise valuable substantive empirical novel model would be developed and can be employed to study iron ore. These concise empirical novel models were outlined below;

- Because all minerals must be set in matrices to form rocks, "Matrix equations" would be used to resolve the problems between iron ores in itakpe and cassiterite

- $\quad$ Because minerals require temperature, pressure and energy to form, two series of reactions are used to establish these relationships, which are the Oxidation and the Titanization.

- Because iron ores are formed from two environments of igneous and sedimentary rocks, they are classified into groups called Periodic Table of an iron ore.

\section{References}

i. Bowen N. L., (1928). The later stages of the Evolution of the Igneous Rocks, Journal of Geology xxiii. Supplement, $91 \mathrm{pp}$.

ii. Burns, R. G., Clark, R. H.« and Fyfe, W. S., 1964, Crystal-field theory and application to / problems in geochemistry, in Chemistry of the Earth's Crust, Vemadsky Centennial Symposium. Vol. 2 (Vinogradov, ed.), Moscow, pp. 88-106.

iii. Burns, R. G., and Fyfe, W. S., 1966, Distribution of elements in geological processes, $t^{\wedge} /$ Chem. Geol., 1, 49-56. BumS, R. G., and Fyfe, W. S., 1967, Trace element distribution rules and their significance, Chem. Geol., 2, 89-104. Burns, R. G., and Fyfe, W. S., 1967, Crystal-field theory and the geochemistry of transition elements, in Researches in Geochemistry, Vol. 2, (Abelson, ed.), Wiley, New ${ }^{\wedge}$ York, pp. 259-285.

iv. Denbigh, K.G., and J.C.R Turner., (1971). Chemical Reactor Theory - An Introduction (Second Ed.). Cambridge, UK: Cambridge Univ. Press (1971). 
v. Goldschmidt, V. M., 1926, Geochemische Verteilungsyesetze der Elemente VII. Die Gesetze der Kristallochemie, Skrfler Norske Videnskaps-Akad. Oslo,'I, Mat. Naturv. Kl, 2, 5-116.

vi. Green, J., 1959, Geochemical table of the elements for 1959, 1127-1184.

vii. Krauskopf, K. B., 1967, Introduction to Geochemistry, McGraw-Hill, New York," 721 pp.

viii. Krumbein, W. c., \& Graybill, F. A., 1965: An introduction to Statistical model in geology Mc Graw- Hill, New York.

ix. Mason, B., 1966, Principles of Geochemistry, Wiley, New York, 329 pp.

x. Mendele'ev D. (1877). Entstehungund Vorkommen des materials Dtsch. Chem. Gas. Ber; 10, 229.

xi. Mendele'ev D. (1902). The principle of chemistry, 2nd English ed; Vol.1, (Translated from 6 ${ }^{\text {th }}$ Russian ed;) Collier, New York.

xii. Nakayama k., and Vansiclen D.C., 1981. Simulation Model for petroleum Exploration:APPG Bull.Vol.65123o1255.

xiii. Pauling, L., 1960, The Nature of the Chemical Bond, 3rd edition, Cornell University Press, Ithaca, New York, 644 pp.

xiv. Pitzer K. S., and Brewer, L., (1961). Thermodynamics (2nd edu). M.C. Graw. Hill, New York.

xv. Price, Leigh C. (1986). A critical review and proposed working model of surface geochemical exploration. In: unconventional methods in exploration IV. Southern Methodist University, Delias, TX, p 245-304.

xvi. Ramberg, H., and Devore, G., 1951. The distribution of $\mathrm{Fe}^{2+}$ and $\mathrm{Mg}^{2+}$ in coexisting olivines and pyroxenes, J. Geo L., 59: 193 - 210.

xvii. Ringwood A. E., (1969). Composition and evolution of the upper mantle, in the Earth's Crust and Upper mantle, ed. P. G. Hart, Amer. Geophys. Union Monogt., 13, 1-17.

xviii. Ringwood, A. E., 1955a, the principles governing trace element distribution during mag- /matic crystallization. Part I. The influence of electronegativity, Geochim. Cosmo- ^ chim. Acta, 7, 189-202. Ringwood, A. E., 1955b, the principles governing trace element behavior during magmatic allization. Part II. The role of complex formation, Geochim. Cosmochim. Acta, 7,242-254.

xix. $\quad$ Ringwood, A.E. 1962. A Model for the Upper Mantle. J. Geophys. Res. 67, 4473 - 4477.

xx. Ringwood, A.E. 1975. Composition and Petrology of the Earth's Mantle. McGraw-Hill, New York.

xxi. Turcotte, D.L., H. Ockendon, J.R., Ockendon, and S.J. Cowley (1990), A Mathematical Model for Vulcanian eruptions, Geophys. J. Int., 103, $211-217$.

xxii. $\quad$ Ungerer, P. etal, Mom. Am. Ass. Petro.Geol.35 (eds Demaison, 6. \& Murris, R) 53-77 (1984).29.

xxiii. Yaro, S.A. and Thomas D.G. (2009): Chemical mineralogical characteristics of kotonkarfe iron ore. Journal of Engineering and Technology (JET). Bayero University. Kano. 4(1). P. 65- 71.

\section{Appendix}

Mathematical Expression of Iron Ore

A1: Ferrous- ferric family:

Ferrous iron ore: $X_{3-\mathrm{x}} \mathrm{O}_{4} / \mathrm{X}_{1-\mathrm{x}} \mathrm{O}$

- Magnetite : $\mathrm{Fe}_{3} \mathrm{O}_{4}$

- Wustite: $\mathrm{FeO}$

Ferric iron ore: $\mathrm{X}_{2-\mathrm{x}} \mathrm{O}_{3}$

- Haematite: $\mathrm{Fe}_{2} \mathrm{O}_{3}$

A2: Titanized iron ore:

Titanohaematite : $\left(\mathrm{X}_{2}-\mathrm{X} \mathrm{Y} x\right) \mathrm{O}_{3}$

- Ilmenite: $\mathrm{FeTiO}_{3}$

- Ilmeno-rutile: $\mathrm{FeTi}_{2} \mathrm{O}_{5}$

Titanomagnetite: $\left(\mathrm{X}_{3}-\mathrm{x} Y \mathrm{x}\right) \mathrm{O}_{4}$

- Ulvospinel: $\mathrm{Fe}_{2} \mathrm{TiO}_{4}$

- Pseudobroockite: $\mathrm{Fe}_{2} \mathrm{TiO}_{5}$

Chemical Classification of Iron Ore With Respect to Titanium to Iron Ratio

B1: group 0: Iron or titanium is absent or present alone in the ore that is any of them is zero in the ore.

- Magnetite

- Haematite

- Wustile

- rutile

B2: group 1: both iron and titanium are present partially or in equal amount, they increase or decrease in amount by one atom.

- Ilmenite

- Ulvospinel

- Pseudobroockite

- Ilmeno rutile 